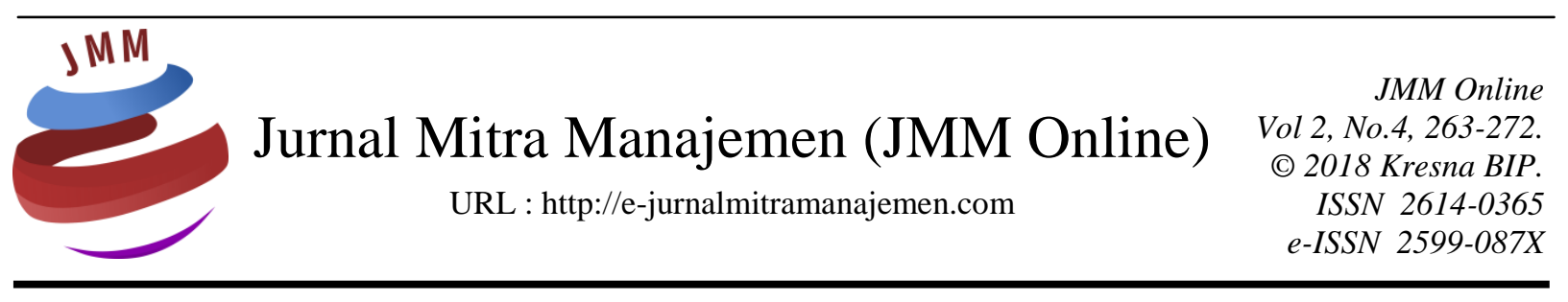

\title{
PENGARUH KOMPENSASI TERHADAP MOTIVASI KERJA KARYAWAN DI BIZNET NETWORKS
}

\author{
Jericho Haganta Sembiring ${ }^{1)}$, Arif Partono Prasetio ${ }^{2)}$ \\ Universitas Telkom
}

\section{INFORMASI ARTIKEL}

Dikirim : 24 Mei 2018

Revisi pertama : 17 Juli 2018

Diterima : 18 Juli 2018

Tersedia online : 28 Juli 2018

Kata Kunci : Sumberdaya Manusia, Kompensasi, Motivasi Kerja

Email : mrjericho7@gmail.com ${ }^{1)}$, partono1905@gmail.com ${ }^{2)}$

\section{ABSTRAK}

Penelitian ini bertujuan untuk mengetahui pengaruh kompensasi terhadap motivasi kerja karyawan. Penelitian ini dilakukan di perusahaan Biznet Networks yang berlokasi di Jakarta Pusat, total responden dalam penelitian ini berjumlah 171 responden dari seluruh karyawan yang ada di perusahaan Biznet Networks. Teknik pengumpulan data yang dilakukan pada penelitian ini dengan cara melakukan penyebaran kuesioner kepada 171 responden. Kuesioner yang digunakan memiliki 43 butir pernyataan dengan skala likert 6 titik. Metode sampling yang digunakan pada penelitian ini yaitu nonprobability sampling dengan teknik convenience sampling. Teknik analisis data yang digunakan pada penelitian ini menggunakan analisis deskriptif, sedangkan teknik analisis regresi linier sederhana digunakan untuk mengetahui pengaruh antara dua variabel yaitu kompensasi dan motivasi. Hasil yang didapat menunjukkan bahwa kompensasi memiliki pengaruh signifikan positif terhadap motivasi kerja karyawan pada perusahaan Biznet Networks, hasil tersebut diharapkan dapat menjadi masukan bagi perusahaan dalam mengelola sistem pemberian kompensasi secara lebih baik lagi agar dapat meningkatkan motivasi kerja karyawan. 


\section{PENDAHULUAN \\ Latar Belakang}

Sumberdaya manusia merupakan bagian terpenting dalam mencapai tujuan sebuah organisasi. Dengan adanya sumberdaya manusia, setiap organisasi dapat mencapai tujuan dan target organisasi yang dapat menciptakan kesuksesan jangka panjang bagi organisasi tersebut. Kesuksesan jangka panjang dari setiap organisasi tergantung pada bagaimana organisasi menempatkan orang yang tepat dalam posisi yang tepat, disertai dengan sistem yang baik untuk menjalankan roda organisasi tersebut (Potale dan Uhing, 2015). Sumber daya manusia yang baik adalah memiliki bakat, tenaga, dan kreativitas serta mampu menggerakkan perusahaan untuk berkembang ke arah yang lebih baik lagi (Rezita, 2014).

Banyak faktor yang mendasari meningkatnya motivasi kerja para karyawan diantaranya ialah budaya organisasi dan kepuasan kerja karyawan yang terpenuhi sehingga mengurangi dampak terjadinya stress kerja terhadap karyawan (Hamali, 2016:53). Selain itu, Rizqiyah et al. (2013) berpendapat bahwa gaya kepemimpinan merupakan faktor yang mempengaruhi motivasi kerja karyawan. Tingkat motivasi kerja karyawan dipengaruhi oleh seberapa besar figur seorang pemimpin dalam perusahaan.

Faktor lain yang menyebabkan meningkatnya motivasi kerja karyawan baik secara sadar ataupun tidak sadar ialah pemberian kompensasi. Ganta (2014) menjelaskan bahwa kompensasi merupakan faktor yang dapat meningkatkan motivasi kerja karyawan yang mampu menciptakan gairah tersendiri bagi karyawan untuk menyelesaikan setiap tanggung jawab yang diberikan oleh perusahaan, oleh karena itu penting bagi perusahaan untuk memperhatikan sistem pemberian kompensasi yang diterapkan untuk menjaga serta meningkatkan motivasi kerja karyawan.

Meningkatnya motivasi kerja karyawan menimbulkan dampak yang positif dan menjadi hal yang sangat penting bagi perusahaan, dengan meningkatnya motivasi kerja karyawan akan mendorong setiap karyawan bekerja keras dalam menyelesaikan seluruh pekerjaannya dan meningkatkan kapabilitas karyawan dalam mencapai tujuan perusahaan (Shahzadi, 2014). Selaras dengan hal tersebut, Khan dan Mufti (2012) menjelaskan bahwa timbulnya motivasi berdampak dalam mendorong seseorang untuk bekerja dan menghasilkan sesuatu sehingga berdampak positif untuk perusahaan.

Penelitian ini akan membahas pengaruh kompensasi terhadap motivasi kerja karyawan pada perusahaan Biznet Networks. Biznet Networks merupakan salah satu perusahaan operator telekomunikasi fixed-line dan operator multimedia yang memberikan layanan jaringan terbesar di Indonesia, dimana setiap karyawan yang terdapat diperusahaan sangat mempertimbangkan apakah kompensasi yang diberikan sudah sesuai dengan usaha yang diberikan dalam membantu perusahaan menggapai target serta tujuan perusahaan. Hasil penelitian ini diharapkan dapat menjadi masukan bagi perusahaan dalam meningkatkan motivasi kerja karyawan dengan cara menerapkan sistem pemberian kompensasi yang baik untuk karyawan.

\section{Rumusan Masalah}

Salah satu permasalahan yang dapat terjadi pada suatu perusahaan ialah rendahnya tingkat motivasi kerja pada karyawan. Tingkat motivasi kerja yang rendah pada para karyawan tentunya dapat merugikan perusahaan salah satunya dengan 
produktivitas kerja karyawan yang menurun dan tidak memberikan kontribusi yang baik kepada perusahaan.

\section{Tujuan Penelitian}

Berdasarkan penjelasan tersebut penelitian ini akan melihat bagaimana pengaruh kompensasi terhadap motivasi karyawan di BiznetNetworks. Penelitian ini dilakukan dengan melihat tingkat persepsi karyawan terhadap pemberian kompensasi dari perusahaan dan tingkat motivasi karyawan di BiznetNetworks serta bagaimana pengaruhnya antara kompensasi terhadap motivasi karyawan di BiznetNetworks.

\section{KAJIAN PUSTAKA Kompensasi}

Kompensasi merupakan alat untuk menciptakan timbulnya dorongan kerja karyawan, yang membuat karyawan lebih memiliki gairah dalam pekerjaannya sehingga membangun rasa nyaman atas pekerjaan yang dimiliki yang kemudian dapat meningkatkan motivasi kerja karyawan (Haryani et al., 2015; Odunlami dan Matthew, 2014).

Banyak faktor yang mempengaruhi penentuan kompensasi terhadap karyawan, diantaranya ialah biaya hidup disuatu daerah. Penentuan besaran kompensasi ditentukan berdasarkan kekuatan ekonomi yang terdapat pada suatu daerah, kemudian faktor lain yang mempengaruhi pengelolaan besaran kompensasi ialah regulasi dari pemerintah, pemberian kompensasi ditentukan oleh upah standar minimum yang ditetapkan pemerintah untuk setiap daerah kerja (Gaol, 2014:3; Negash et al., 2014).

Selain itu, faktor lain yang mempengaruhi kompensasi ialah prestasi kerja. Sari (2015:2) menjelaskan prestasi kerja berpengaruh dengan pemberian kompensasi dari perusahaan. Semakin banyak prestasi yang dihasilkan karyawan maka semakin menarik pula kompensasi yang diberikan perusahaan dan hal tersebut akan menciptakan persaingan positif bagi setiap karyawan untuk memperoleh prestasi dalam pekerjaan.

Dampak dari pemberian kompensasi juga dapat mempengaruhi perilaku individu. Noe et al. (2011:54) menuturkan individu pada suatu organisasi dapat membandingkan kompensasi yang diperoleh dengan kompensasi yang didapatkan oleh rekannya yang kemudian mempengaruhi perilaku individu apabila terdapat kesenjangan dalam pemberian kompensasi. Menurut Laminingrum (2016) kompensasi yang menarik dan tepat waktu juga berpengaruh dalam meningkatkan motivasi kerja karyawan.

Kusuma et al. (2014:45) menguraikan bahwa kompensasi terdiri atas dua dimensi yaitu kompensasi finansial dan kompensasi non finansial. Kompensasi finansial terdiri atas bayaran pokok baik itu gaji atau upah, bonus, insentif dan tunjangan-tunjangan. Sementara itu kompensasi non finansial dapat berupa sarana kantor yang baik, kebijakan perusahan serta lingkungan kerja yang kondusif. Peneliti menggunakan alat ukur yang digunakan oleh Hasibuan (2012) yaitu kompensasi lansung dan kompensasi tidak lansung. 


\section{Motivasi Kerja}

Motivasi merupakan hal yang mendorong individu untuk bekerja didalam sebuah organisasi (Ganta, 2014). Motivasi juga dapat diartikan sebagai suatu dorongan dari seorang individu yang timbul karena pengaruh tertentu yang kemudian mendorong individu untuk bekerja secara maksimal dan optimal (Chintallo dan Mahadeo, 2013; Khan dan Mufti, 2012).

Faktor-faktor yang mempengaruhi meningkatnya motivasi kerja pada setiap individu diantaranya adalah faktor promosi jabatan terhadap individu dalam suatu organisasi, dengan diberikannya promosi jabatan kebutuhan akan adanya jenjang karir yang lebih baik akan terwujud. Setelah itu adanya faktor pemberian insentif, intensif merupakan upah atau gaji yang diberikan berbeda karena prestasi kerja yang berhasil diraih oleh karyawan yang dapat mendorong motivasi karyawan untuk bekerja lebih baik (Khotimah et al., 2015; Prakoso et al., 2014).

Meningkatnya motivasi kerja pada karyawan juga berperan penting untuk membantu perusahaan dalam meningkatkan mutu karyawan dan berdampak terhadap produktivitas karyawan yang meningkat serta dengan motivasi kerja yang tinggi karyawan akan bekerja sesuai dengan harapan perusahaan dan menghasilkan kinerja yang baik (Syaiyid et al., 2013).

Dengan meningkatnya motivasi kerja yang tinggi pada setiap karyawan akan bekerja secara efektif dan efisien dalam menyelesaikan setiap pekerjaan yang diberikan dan mengerahkan segala upaya untuk mendapatkan hasil yang maksimal sesuai dengan standar perusahaan (Panagiotis et al., 2014).

Chintallo \& Mahadeo (2013:3-4) mengemukakan bebearapa indikator yang digunakan dalam mengukur motivasi kerja diantaranya ialah: Physicological needs, safety needs, belonging needs, esteem needs dan self-actualization. Penulis menggunakan alat ukur yang telah digunakan Schermerhorn (2012) yaitu dengan menggunakan teori yang berfokus kepada tiga kebutuhan yaitu need for power, need for achievement dan need for affiliation.

\section{Hubungan Kompensasi dengan Motivasi Kerja}

Penelitian mengenai pengaruh kompensasi terhadap motivasi kerja sudah dilakukan oleh beberapa peneliti diberbagai negara seperti Pakistan, Saudi Arabia, China, dan Indonesia dengan objek penelitian yang berbeda-beda seperti, Universitas, airport, bank, lembaga audit, perusahaan telekomunikasi, perusahaan otomotif, perbankan dan perusahaan yang bergerak di bidang logistik. Penelitian tersebut menunjukan bahwa kompnesasi berpengaruh signifikan positif terhadap motivasi kerja karyawan (Negash et al. 2014; Arshad et al. 2012; Aamir et al. 2012; Rizal et al. 2014; Haryani et al. 2015; Ulfa et al. 2013; Khan dan Mufti 2012; Wulansari et al. 2014; Ghazanfar et al. 2015; Gunawan 2015).

\section{Tabel 1. Perbandingan Hasil Penelitian Terdahulu}

\begin{tabular}{llll}
\hline Penulis dan Tahun & Negara atau Kota & Objek Penelitian & $\mathrm{R}$ \\
\hline Negash et al, 2014 & Pakistan & Universitas & 0,795 \\
Arshad et al, 2012 & Pakistan & Bandara & $0,173^{*}$ \\
Aamir et al, 2012 & Saudi Arabia & Perbankan & 0,763
\end{tabular}




\section{Lanjutan Tabel 1. Perbandingan Hasil Penelitian Terdahulu}

\begin{tabular}{|c|c|c|c|}
\hline Rizal et al, 2014 & Indonesia & Lembaga Audit & 0,832 \\
\hline Haryani et al, 2015 & Indonesia & $\begin{array}{l}\text { Perusahaan } \\
\text { Telekomunikasi }\end{array}$ & 0,821 \\
\hline Ulfa et al, 2013 & Indonesia & $\begin{array}{l}\text { Perusahaan } \\
\text { Otomotif }\end{array}$ & 0,327 \\
\hline Khan dan Mufti, 2012 & Pakistan & Bank & 0,870 \\
\hline Ghazanfar et al, 2015 & China & Perusahaal Seluler & 0,342 \\
\hline Wulansari et al, 2014 & Indonesia & PLN & 0,698 \\
\hline Gunawan, 2015 & Indonesia & $\begin{array}{l}\text { Perusahaaan } \\
\text { Logistik }\end{array}$ & 0,379 \\
\hline
\end{tabular}

Berdasarkan penelitian terdahulu yang telah dijelaskan sebelumnya, menunjukkan bahwa kompensasi memiliki pengaruh signifikan positif terhadap motivasi kerja. Hal ini sudah dibuktikan oleh penelitian yang telah dilakukan dibeberapa negara yang berbeda. Adapun hipotesis dalam penelitian ini adalah:

$\boldsymbol{H}_{\mathbf{1}}$ : Terdapat pengaruh signifikan positif dari kompensasi terhadap motivasi kerja karyawan

\section{METODE PENELITIAN}

Populasi dari penelitian ini adalah 300 orang karyawan Biznet Networks. Teknik sampling yang digunakan adalah convenience sampling. Berdasarkan perhitungan menggunakan rumus slovin sampel yang dilibatkan pada penelitian ini adalah 171 orang karyawan secara acak meliputi admin, pelaksana, supervisor dan manager dan waktu penelitian dilakukan pada bulan Mei 2018 - Juli 2018 Detail demografis responden disajikan pada Tabel 2.

Data yang terdapat pada penelitian ini diperoleh melalui kuesioner. Kuesioner penelitian menggunakan 25 item pertanyaan untuk mengukur sistem pemberian kompensasi yang pernah dipakai oleh Hasibuan (2012) dengan contoh item pertanyaan "Gaji pokok yang diberikan dapat memenuhi kebutuhan sehari-hari" dan 18 item pertanyaan untuk mengukur tingkat motivasi kerja karyawan yang pernah dipakai oleh Schermerhorn (2012) dengan contoh item pertanyaan "Senang menerima tanggung jawab yang diberikan atasan".

Skala yang digunakan adalah skala likert 6 poin, yaitu Skala 6 (sangat setuju), 5 (setuju), 4 (ragu cenderung setuju), 3 (ragu cenderung tidak setuju), 2 (tidak setuju), 1 (sangat tidak setuju).Teknik analisis yang digunakan pada penelitian ini adalah analisis deskriptif dan penelitian ini menggunakan analisis regresi linier sederhana untuk mengetahui arah hubungan pengaruh kompensasi terhadap motivasi kerja karyawan Biznet Networks.

Pada penelitian ini menggunakan uji reliabilitas dengan menggunakan Cronbach's Alpha dengan nilai yang dihasilkan sebesar 0,973 untuk variabel (X) kompensasi, sedangkan untuk variabel (Y) motivasi kerja nilai pada Cronbach's Alpha dihasilkan sebesar 0,965. Penelitian ini menguji pengaruh variabel kompensasi sebagai variabel independent terhadap motivasi kerja sebagai variabel dependent. 
Tabel 2. Aspek Geografis

\begin{tabular}{|c|c|c|c|}
\hline $\begin{array}{l}\text { Faktor } \\
\text { Demografi }\end{array}$ & Klasifikasi & $\begin{array}{l}\text { Jumlah } \\
\text { Responden }\end{array}$ & Presentase \\
\hline \multirow{4}{*}{ Jenis Kelamin } & Pria & 109 & $64 \%$ \\
\hline & Wanita & 62 & $36 \%$ \\
\hline & $<25$ Tahun & 81 & $47 \%$ \\
\hline & 25-30 Tahun & 81 & $47 \%$ \\
\hline \multirow{4}{*}{ Usia } & $>30-35$ Tahun & 8 & $5 \%$ \\
\hline & $>35-40$ Tahun & 1 & $1 \%$ \\
\hline & $>40-45$ Tahun & 0 & $0 \%$ \\
\hline & $<50$ Tahun & 0 & $0 \%$ \\
\hline \multirow[t]{5}{*}{ Lama Bekerja } & $<1$ Tahun & 22 & $12 \%$ \\
\hline & 1-3 Tahun & 121 & $71 \%$ \\
\hline & $>3-5$ Tahun & 24 & $14 \%$ \\
\hline & $>5-10$ Tahun & 4 & $3 \%$ \\
\hline & $>10$ Tahun & 0 & $0 \%$ \\
\hline \multirow[t]{3}{*}{$\begin{array}{l}\text { Posisi } \\
\text { Pekerjaan }\end{array}$} & $\begin{array}{l}\text { Non Jabatan (Pelaksana, } \\
\text { Admin, officer) }\end{array}$ & 166 & $97 \%$ \\
\hline & Supervisor & 2 & $1 \%$ \\
\hline & Manajer & 3 & $2 \%$ \\
\hline \multirow[t]{3}{*}{ Pendidikan } & SMA/SMK & 0 & $0 \%$ \\
\hline & Diploma & 37 & $21 \%$ \\
\hline & $\mathrm{S} 1$ & 134 & $79 \%$ \\
\hline \multirow[t]{2}{*}{ Waktu Kerja } & $\begin{array}{l}\text { Sampai dengan } 9 \text { jam per } \\
\text { hari }\end{array}$ & 168 & $98 \%$ \\
\hline & Lebih dari 9 jam per hari & 3 & $2 \%$ \\
\hline
\end{tabular}

Sumber : Data Olahan Penulis (2018)

\section{HASIL PENELITIAN DAN PEMBAHASAN}

Dalam penelitian ini peneliti menggunakan uji asumsi klasik dan uji regresi linier sederhana. Uji asumsi klasik dilakukan untuk mengetahui apakah data layak digunakan atau tidak, uji asumsi klasik terdiri dari uji normalitas dan heteroskedastisitas. Uji normalitas dilakukan menggunakan metode uji one-sample kolmoogrov smirnov dan untuk uji heteroskedastisitas menggunakan uji Glejser.

Penelitian ini menggunakan IBM SPSS 24 dalam melakukan pengolahan data. Hasil pengolahan data pada uji normalitas disajikan pada tabel 3 yang menunjukkan Asymp. Sig. (2-tailed) sebesar 0,200 yang artinya data dalam penelitian ini masuk dalam kategori normal karena nilai Asymp.Sig. (2-tailed) $>0,05$. Sedangkan pada uji Heteroskedastisitas yang tertera pada tabel 4 menunjukkan bahwa nilai signifikansi yang diperoleh ialah sebesar 0,341 yang menjelaskan bahwa nilai signifikansi yang diperoleh $>0,05$. Dengan demikian data dalam penelitian ini dikatakan lolos uji asumsi klasik. 
Tabel 3. Uji Normalitas

\begin{tabular}{ll}
\hline \multicolumn{2}{l}{ One-Sample Kolmogorov-Smirnov Test } \\
\hline $\mathrm{N}$ & Unstandardized Residual \\
\hline Asymp.Sig. (2-tailed) & 171 \\
\hline
\end{tabular}

Sumber : Hasil Penelitian, diolah (2018)

Tabel 4. Uji Heteroskedastisitas

\begin{tabular}{lllll}
\hline \multirow{2}{*}{ Model } & \multicolumn{2}{l}{ Unstandardized Coefficients } & \multirow{2}{*}{ t } & Sig. \\
1 & B Constant $)$ & 0.684 & 5.038 & 0.000 \\
& Kompensasi & -0.034 & 0.954 & 0.341 \\
\hline
\end{tabular}

Sumber : Hasil Penelitian, diolah (2018)

Pembahasan selanjutnya mengenai hasil uji regresi linier sederhana. Analisis ini digunakan untuk mengukur kekuatan hubungan linier antara variabel. Pada tabel 5, menunjukkan hasil perhitungan uji regresi linier sederhana dengan hasil konstanta sebesar 1.914 yang berarti bahwa nilai konsisten variabel motivasi sebesar 1.914. Koefisien regresi kompensasi sebesar 0,442 menyatakan bahwa setiap penambahan $1 \%$ nilai kompensasi, maka nilai Motivasi bertambah sebesar 0,442. Koefisien regresi tersebut bernilai positif, sehingga dapat dikatakan bahwa arah pengaruh kompensasi terhadap motivasi adalah positif.

Tabel 5. Analisis Regresi Linier Sederhana

\begin{tabular}{lll}
\hline Model & B & Sig. \\
\hline 1 (Constant) & 1,914 & 0,000 \\
Kompensasi & 0,442 & 0,000 \\
\hline
\end{tabular}

Sumber : Hasil Penelitian, diolah (2018)

Tabel 6 menunjukkan nilai signifikansi yang dihasilkan sebesar $0,000<0,05$. Berdasarkan hasil nilai signifikansi yang diperoleh model regresi dapat dipakai untuk memprediksi variabel kompensasi memiliki pengaruh terhadap variabel motivasi.

Hasil selanjutnya adalah uji koefisien determinasi pada tabel 7 didapatkan nilai R Square sebesar 0,196 atau 19,6\% yang mengandung pengertian bahwa pengaruh variabel motivasi terhadap variabel terikat kompensasi adalah sebesar 19,6\%.

Tabel 6. Hasil Uji Anova

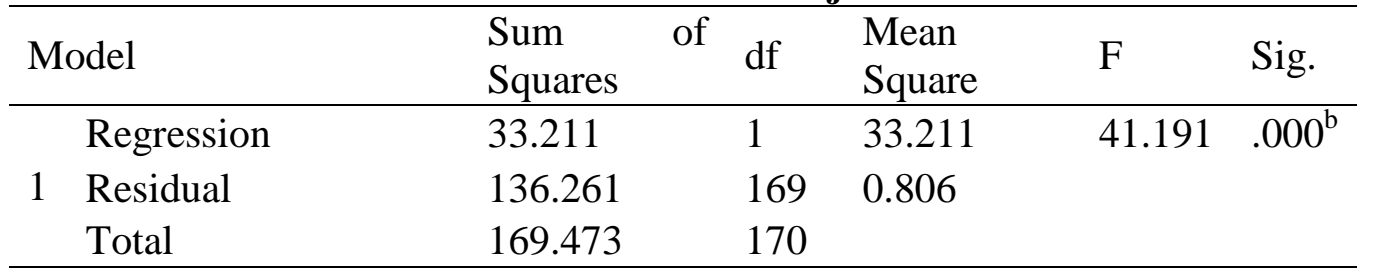

Sumber : Hasil Penelitian, diolah (2018) 
Tabel 7. Hasil Uji Koefisien Determinasi

\begin{tabular}{|c|c|c|c|c|}
\hline \multicolumn{5}{|c|}{ Model Summary } \\
\hline Model & $\mathrm{R}$ & R Square & $\begin{array}{ll}\text { Adjusted } & R \\
\text { Square } & \end{array}$ & $\begin{array}{l}\text { Std. Error of } \\
\text { the Estimate }\end{array}$ \\
\hline 1 & $.443^{\mathrm{a}}$ & 0.196 & 0.191 & 0.89793 \\
\hline
\end{tabular}

Hasil penelitian ini menunjukan bahwa kompensasi berpengaruh signifikan positif terhadap motivasi kerja karyawan Biznet Networks. Ketika sistem pemberian kompensasi yang diberikan kepada karyawan baik, akan mempengaruhi motivasi kerja karyawan dalam melakukan setiap kegiatan di perusahaan dalam upaya membantu perusahaan untuk mencapai tujuan perusahaan.

Dalam penelitian ini hasil yang didapat selaras dengan hasil-hasil penelitian sebelumnya yang mengungkapkan bahwa kompensasi memiliki hubungan signifikan positif terhadap motivasi kerja. Hasil penelitian tersebut ditemukan oleh penelitian terdahulu yaitu (Negash et al. 2014; Arshad et al. 2012; Aamir et al. 2012; Rizal et al. 2014; Haryani et al. 2015; Ulfa et al. 2013; Khan dan Mufti 2012; Wulansari et al. 2014) yang membuktikan bahwa kompensasi berpengaruh signifikan positif terhadap motivasi kerja.

Sistem pemberian kompensasi yang diterapkan Biznet Networks memiliki pengaruh positif terhadap motivasi kerja karyawan, namun masih banyak faktor lain yang dapat mempengaruhi tingkat motivasi kerja karyawan seperti budaya organisasi, lingkungan kerja dan juga stress kerja. Penting bagi perusahaan untuk memperhatikan beberapa aspek tersebut agar tingkat motivasi kerja karyawan tetap stabil dan meningkat.

Perusahaan Biznet Networks sendiri memiliki reputasi yang baik pada industri jaringan terkhususnya di indonesia. Perusahaan sendiri sudah memiliki banyak cabang yang tersebar luas di indonesia terkhususnya memenuhi kebutuhan setiap konsumen untuk mengakses internet dengan koneksi yang cepat sehingga dapat mewujudkan mimpi perusahaan untuk mengurangi kesenjangan digital indonesia dengan negaranegara berkembang lainnya.

\section{KESIMPULAN}

Berdasarkan hasil penelitian yang didapat bahwa kompensasi berpengaruh signifkan positif terhadap motivasi kerja karyawan Biznet Networks. Hasil penelitian ini mendukung hipotesis $H_{1}$ yang telah ditentukan sebelumnya oleh penulis yang menyatakan bahwa terdapat pengaruh signifikan positif dari kompensasi terhadap motivasi kerja karyawan. Berdasarkan hasil wawancara bahwa lingkungan kerja juga merupakan hal yang dapat mempengaruhi motivasi kerja karyawan.

Semakin baik sistem pemberian kompensasi yang dilakukan maka akan berpengaruh terhadap meningkatnya motivasi kerja karyawan, begitupun sebaliknya semakin buruk sistem pemberian kompensasi yang dilakukan maka akan semakin rendah pula motivasi kerja karyawan. Maka dari itu, penting bagi perusahaan mengelola sistem pemberian kompensasi secara adil dan transparan.

Pada penelitian ini, penulis fokus pada dua variabel independent dan dependent, oleh karena itu besar harapan penulis agar penelitian selanjutnya dapat meneliti lebih dari dua variabel. Tidak hanya itu, penulis juga berharap untuk peneliti selanjutnya 
dapat meneliti perusahaan telekomunikasi yang lain ataupun perusahaan yang bergerak dibidang TIK di daerah lain atau kota lain. Karena penelitian ini hanya terfokus kepada perusahaan Biznet Networks di Jakarta Pusat.

\section{SARAN}

Mengingat kompensasi mempunyai pengaruh positif terhadap motivasi kerja pada karyawan PT. Supra Primatama Nusantara, maka diharapkan perusahaan dapat memberikan kompensasi yang sesuai dengan prestasi karyawan terhadap perusahaan. Sehingga motivasi kerja karyawan dapat meningkat dan tujuan perusahaan dapat tercapai bersama, dan bagi peneliti berikutnya diharapkan hasil penelitian ini dapat dipakai sebagai acuan penelitian selanjutnya untuk mengembengkan penelitian ini dengan menggunakan variabel-variabel lain diluar penelitian ini yang diharapkan mampu untuk meningkatkan motivasi kerja karyawan.

\section{DAFTAR PUSTAKA}

Aamir, A., Jehanzeb, K., Rasheed, A., \& Malik, O. M. 2012. Compensation Methods and Employees' Motivation (With Reference to Employees of national Commercial Bank Riyadh). International Journal of Human Resource Studies.

Arshad, M., Safdar, Muhammad, Din, U. Q., \& Ellahi, S. 2012. Does Salary Work as a motivational Agent? Study of Airport (Ground Handling) Services Sector in Pakistan. School of Doctoral Studies (European Union) Journal.

Ganta, V. C. 2014. Motivation in the Workplace to Improve The Employee Performance. International Journal of Engineering Technology, Management and Applied Science.

Ghazanfar, F., Chuanmin , S., Khan, M. M., \& Bashir, M. 2011. A Study of Relationship between Satisfaction with Compensation and Work Motivation. International Journal of Business and Social Science.

Gunawan, M. A. 2015. "Pengaruh Kompensasi Finansial dan NonFinansial Terhadap Motivasi Kerja Karyawan PT.Freight Express Surabaya”. Vol. 3, No. 1.

Hamali, Y. A. 2016. Pemahaman Manajemen Sumber Daya Manusia (1 $1^{\text {st }}$ ed). Yogyakarta: Center for Academic Publishing Service.

Haryani, S. S., Hamid, D., \& Susilo, H. 2015. Pengaruh Kompensasi Terhadap Motivasi Kerja dan Kinerja (Studi pada Karyawan PT. Telekomunikasi Indonesia,TBK Malang). Jurnal Administrasi Bisnis.

Hasibuan, M. 2012. Manajemen Sumber Daya Manusia. Jakarta: PT Bumi Aksara.

Khan, W., dan Mufti, O. 2012. Effect of Compensation on Motivating Employees in Public and Private Bank of Peshawar (BOK and UBL). Journal of Basic and Applied Scientific Research Vol.2, No.5.

Khotimah, K., Al-Musadieq, M., \& Hakam, M. S. 2015. Pengaruh Promosi Jabatan dan Insentif Terhadap Motivasi Kerja (Studi pada karyawan PT.PLN (Persero) Distribusi Jawa Timur Area Malang). Jurnal Administrasi Bisnis Vol. 25 No. 1.

Kusuma, Y. B., Swasto, B., \& Al-Musadieq, M. 2014. Pengaruh Kompensasi Terhadap Motivasi Kerja, Kepuasan Kerja, dan Kinerja Karyawan (Studi pada Karyawan Tetap PT. Otsuka Indonesia di Lawang, Malang). 
Laminingrum, A. K. 2016. Pengaruh Kompensasi Terhadap Motivasi Kerja Pada Karyawan Biro Pelayanan Sosial Dasar Di Sekretariat Daerah Provinsi Jawa Barat. e-Proceeding of Management : Vol. 3 , No. 2.

Negash, R., Zewude, S., \& Megarsa, R. 2014. The Effect of Compensation on Employee Motivation: In Jimma University Academic Staff. Basic Research Journal.

Noe, A, R., Hollenback, R, John., Gerhart, ., Wright, P. M. 2008. Human Resource Management: Gaining a Competitive Advantage (ed) Avenue of The Americas, NY: McGraw-Hill.

Odunlami, I. B., \& Matthew, A. O. 2014. Compensation Management and Employees Performance in the Manufacturing Sector, A Case Study of a Reputable Organization In the Food and Beverage Industry. International Journal Of Managerial Studies and Research: Vol. 2, No. 9.

Panagiotis, M., Alexandros , S., \& George, P. 2014. Organizational Culture and Motivation in the Public Sector. The Case of the City of Zografou. Procedia Economics and Finance.

Potale, R., \& Uhing, Y. 2015. Pengaruh Kompensasi dan Stress Kerja Terhadap Kepuasan Kerja Karyawan Pada PT.Bank Sulut Cabang Utama Manado. Jurnal EMBA Vol. 3, No. 1 .

Prakoso, R. D., Astuti, E. S., \& Ruhana, I. 2014. Pengaruh Lingkungan Kerja Terhadap Motivasi Kerja dan Kinerja Karyawan (Studi Pada Karyawan PT.AXA Financial Indonesia Cabang Malang). Jurnal Administrasi Bisnis: Vol. 14, No. 2.

Rezita, R. 2014. Pengaruh Lingkungan Kerja Terhadap Motivasi Kerja Karyawan di Bank Jatim Cabang Utama Surabaya.

Rizal, M., Idrus, M. S., \& Mintarti, R. 2014. Effect of Compensation on Motivation, Organizational Commitment and Employee Performance (Studies at Local Revenue Management in Kendari City. International Journal of Business and Management Invention. Vol.3, No.2.

Rizqiyah, I. A., Rahardjo, K., \& Utami, H. N. 2013. Pengaruh Gaya Kepemimpinan Terhadap Motivasi Kerja Karyawan (Studi pada Karyawan PT. Temprina Medika Grafika Surabaya).

Sari, E. L. 2015. Pengaruh Pemberian Kompensasi Terhadap Produktivitas Kerja Karyawan Pada PT Ryan Jaya Persada. Jurnal Ilmu dan Riset Manajemen. Vol. 4, No. 12.

Shahzadi, I., Javed, A., Pirzada, S., Nasreen, S., \& Khanam, F. 2014. Impact of Employee Motivation on Employee Performance. European Journal of Business and Management. Vol. 6, No. 23.

Syaiyid, E., Utami, H. N., \& Riza, M. F. 2013. Pengaruh Gaya Kepemimpinan Terhadap Motivasi Kerja (Studi Pada Karyawan Radar Malang PT. Malang Intermedia Pers). Jurnal Administrasi Bisnis. Vol. 1, No. 1.

Ulfa, M., Rahardjo, K., \& Ruhana, I. 2013. Pengaruh Kompensasi Terhadap Motivasi Kerja dan Kinerja Karyawan (Studi pada Karyawan Auto 2000 Malang Sutoyo).

Wulansari, P., Damanik, A.H., Prasetio, A.P. 2014. Pengaruh Kompensasi Terhadap Motivasi Karyawan di Departemen Sumber Daya Manusia PLN Kantor dan Distribusi Jawa Barat dan Banten. Jurnal Manajemen Indonesia. Vol.14, No.2. 